\title{
TU/e EnNHONEN

\section{Visual conspicuity, visual search and fixation tendencies of the eye}

Citation for published version (APA):

Engel, F. L. (1977). Visual conspicuity, visual search and fixation tendencies of the eye. Vision Research, 17(1), 95-108. https://doi.org/10.1016/0042-6989(77)90207-3

DOI:

10.1016/0042-6989(77)90207-3

Document status and date:

Published: 01/01/1977

\section{Document Version:}

Publisher's PDF, also known as Version of Record (includes final page, issue and volume numbers)

\section{Please check the document version of this publication:}

- A submitted manuscript is the version of the article upon submission and before peer-review. There can be important differences between the submitted version and the official published version of record. People interested in the research are advised to contact the author for the final version of the publication, or visit the $\mathrm{DOI}$ to the publisher's website.

- The final author version and the galley proof are versions of the publication after peer review.

- The final published version features the final layout of the paper including the volume, issue and page numbers.

Link to publication

\section{General rights}

Copyright and moral rights for the publications made accessible in the public portal are retained by the authors and/or other copyright owners and it is a condition of accessing publications that users recognise and abide by the legal requirements associated with these rights.

- Users may download and print one copy of any publication from the public portal for the purpose of private study or research.

- You may not further distribute the material or use it for any profit-making activity or commercial gain

- You may freely distribute the URL identifying the publication in the public portal.

If the publication is distributed under the terms of Article 25fa of the Dutch Copyright Act, indicated by the "Taverne" license above, please follow below link for the End User Agreement:

www.tue.nl/taverne

Take down policy

If you believe that this document breaches copyright please contact us at:

openaccess@tue.nl

providing details and we will investigate your claim. 


\title{
VISUAL CONSPICUITY, VISUAL SEARCH AND FIXATION TENDENCIES OF THE EYE
}

\author{
F. L. ENGEL \\ Institute for Perception Research, Den Dolech 2. Eindhoven. The Netherlands
}

(Receired 24 October 1975; in revised form 2 June 1976)

\begin{abstract}
The cumulative probability of target discovery during search has been related experimentally to the relevant "conspicuity area", the visual field in which the target can be discovered after a single eye fixation. During search. "non-targets" were found to be fixated spontaneously in proportion to their conspicuity area.

Further small spontaneous eye fluctuations are described that occurred, during determination of the conspicuity areas, in the direction of the target discovered. Their occurrence and delay depended on the target eccentricity and the size of the conspicuity area.

The resuits emphasize the relevance of the conspicuity area to research on visual selection.
\end{abstract}

Key Words-visual conspicuity: visual search; spontaneous eve movements; selective attention.

\section{(1) INTRODLCTION}

In looking around, our eyes perform a first selection of the generally large amount of available visual information. This paper has to do with the intriguing question as to what factors determine the subject's choice of successive fixations. In particular we examined whether there is a relation between eye movements during search and visual conspicuity defined as the amount of prominence of a visual object in its surroundings.

Earlier we had investigated certain factors that infuence visual selection during a single eye pause. We then specifically considered external and internal determinants of selective attention; visual conspicuity was defined as an external determinant (Engel, 1971). We associated with each object in its background a so-called conspicuity area, the retinal field in which the object is capable of being noticed during a single eye pause, when the subject has no foreknowledge of its location. We proposed the size of this area as a measure of the conspicuity of the object in its particular background. If presented within this area, the object has been assumed to be capable of controlling selective attention by its visual conspicuity.

Since eye movements are generally regarded as bearing a relation to visual attention (e.g. Sanders, 1963; Jeannerod, Gérin and Pernier, 1968; LevySchoen, 1969a; Noton and Stark. 1971), it seemed logical to investigate more closely the possible connections between visual conspicuity and eye movements. For that purpose eye movements were recorded during the performance of a number of visual search tasks. In these experiments the stimulus always consisted of a random dot pattern as background and two dissimilar disks as test objects (see Fig. 1).

The observers were required to search for one specified test object, the "target", and to avoid fixation of the other test object irrelevant to the search task, the "non-target". By analyzing the eye movements made, we were able to relate the visual conspi- cuities of the test objects to their probability of fixation under these two conditions.

In Section 3 the conspicuity area determinations are described, the results of which we needed for the evaluation of the search experiments. Here we discovered a new phenomenon. It was found that although strict fixation of the display centre was required, there frequently occurred a small spontaneous eye movement of about $0.7^{\circ}$ visual angle in length, in the direction of the discovered target. Since the characteristics of these "target-eye movements" supplied a new clue for understanding the way in which visual conspicuity influences eye movements and selective attention, some of their aspects are evaluated in Section 4. In the first reading of this paper, however, Section 4 may be passed over. In Section 5 we relate the conspicuity area data with the cumulative probability of discovering the target as a function of search time, while in Section 6 we consider the tendency to fixation on the non-targets as a function

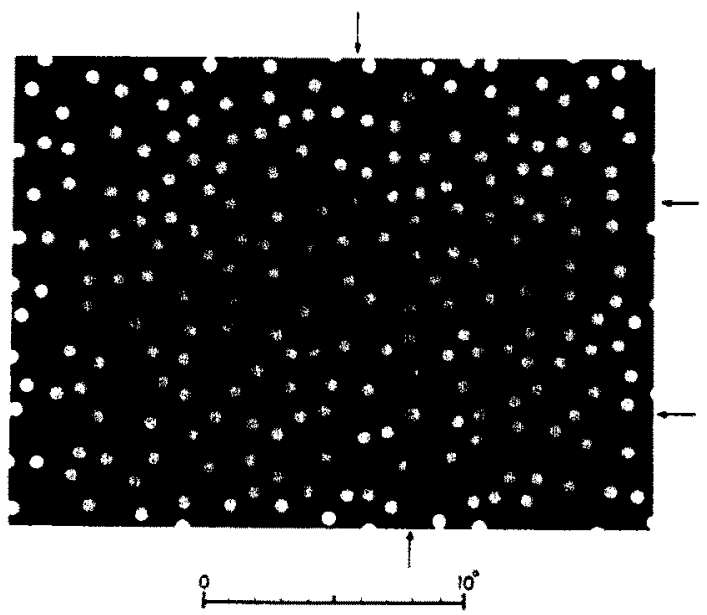

Fig. 1. Example of the stimulus material used: Besides the background disks, the pattern contains a smaller and a larger test disk. The arrows, pointing to their locations, are added for helping the reader to find them. 
of their conspicuity. Finally, in Section 7 there is a general discussion including a tentative diagram of selective information reduction. which is intended to provide a framework for the experimental results obtained.

\section{(2) EXPERIMEYTAL}

\section{(2.1) Stimuli and apparatus}

As already indicated in Fig. 1, the stimuli in the search experiments consisted of randomly located background disks, all of them identical, on a dark ground and among them two different test disks. For the conspicuity area determinations (Section 3), however, the patterns only contained one test disk. the target. In the stimulus patterns overlapping of disks was prevented by maintaining a minimum centre-to-centre distance of 1.5 times the diameter of the background disks. The stimulus patterns were presented to the observer via a TV monitor screen. By shifting the field of view of the TV camera, one of the test objects, e.g. the target, could be located at any desired location on the screen, while the background pattern always compietely filled the display. By doing so, new stimulus patterns became available, in which the configuration of background disks remained the same relative to the test object concemed. The observer was not much aided in his tasks by this fact, due to the random structure of the pattern.

Series of such stimulus patterns shifted each time. were prerecorded on a video tape. The patterns were separated in time by a plain rest field with a fixation cross in the centre. In the successive exposures the pattern was shifted in such a way that the relevant test object occupied in random sequence all the intersections of an imaginary grid across the monitor screen. In the conspicuity area experiments of Section 3 we used a circular grid with 50 intersections around the centre of the screen (Fig. 2a). The grid size was roughly adapted to the expected size of the conspicuity area concerned. In the search experiments of Sections 5 and 6 , we used a rectangular grid with $6 \times 8$ intersections that covered the whole display (Fig. 2b).

In the search experiments, where two test objects were always presented simultaneously, only the first was posi-
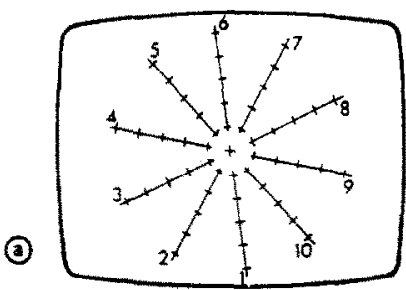

(b)

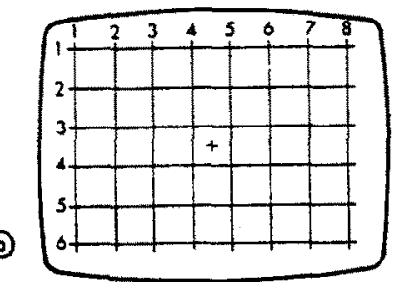

Fig. 2. (a) In the conspicuity-area experiments the target object occupied in random sequence all the intersections of the indicated circular grid, the size of which has been adapted roughly to the expected size of the conspicuity artas concerned. (b) In the search experiments a rectangular grid covering the whole display has been used. Therefore the probability of test object appearance was roughly constant over the screen.

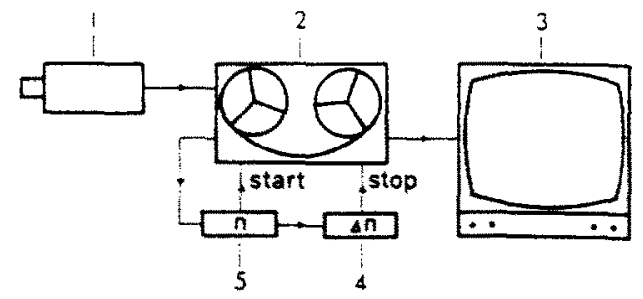

Fig. 3. Set-up for recording the stimulus material. During playback, clock impulses are counted up to an adjustable number $(n)$, after which the video recorder is electronically switched into the insert mode, so that a new picture is recorded for $\Delta n$ sec. $1=T V$ camera: 2 = video tape recorder; $3=$ TV monitor; 4 and $5=$ adjustable pulse counter.

tioned precisely on the selected intersection by alignment of the camera. In view of the requirement of a minimum distance between objects, the location of the second test object, determined by a different random sequence, was at the position of the background disk nearest to the selected intersection. As the prerecorded stimulus series were presented more than once to the same observer. each series started with 5 extra stimulus patterns. used as dummies. Besides serving to warm up the observer, they decreased the possible influence of acquired knowledge con. cerning the first few target locations.

By means of $1-\mathrm{sec}$ clock impulses recorded in advance on one of the sound tracks, and with the picture-insert facility of the video tape recorder (Sony $320 \mathrm{CE}$ ). which did not erase these clock impulses during recording we were able to program the successive stimulus pattern durations in 1-sec multiples. The insert facility on the tape recorder supplied smooth joints between the successive pictures. Figure 3 gives an outline of the set up for recording the stimuli.

The durations of the stimulus fields were 1 sec each for the conspicuity area determinations (Section 3), while they were $4 \mathrm{sec}$ each in the search experiments (Sections 5 and 6). The rest field durations were always $1 \mathrm{sec}$ each. The density of background disks was not changed; therefore the stimulus patterns always contained some 220 back. ground disks. At the maintained viewing distance of 57 $\mathrm{cm}$. the dimensions of the TV screen corresponded to $22.3 \times 16.8^{\circ}$ of visual angle, while the diameter of the background disks on the TV screen resulted in a visual angle of $0.55^{\circ}$. As test objects we used disks with diameters corresponding to the following visual angles on the monitor screen; $0.34^{\circ}, 045^{\circ}, 0.63^{3}$ and $0.69^{\circ}$. These values were chosen such as to ensure a suitable range of conspicuity area sizes.

For all disks the fuminance was $11.5 \mathrm{~cd} \mathrm{~m}^{2}$, while it amounted to $0.45 \mathrm{~cd} / \mathrm{m}^{2}$ for the dark ground and 0.34 $\mathrm{cd} / \mathrm{m}^{2}$ for the plain rest fields. The luminances were measured at the centre of the TV screen and at the eye position of the observer. Due to "vignetting" of the TV tube, all screen luminances gradually decreased towards the borders by some $15^{\circ}$. Since the test disks were distinguished from the background by differences in diameter. this shortcoming was considered to be of minor importance for the findings to be presented.

The eye movements were measured by means of the cornea-reflection technique (e.g. Mackworth and Mackworth, 1958). Figure 4 gives an outline of the setup that we used.

Although vision was binocular. only movements of the observer's left eye were recorded. This was done by direct. ing a near i.r. light beam $(\lambda>770 \mathrm{~nm})$ towards the left eye. This light was invisible to the observer. although not to the i.r. sensitive Silicon-Vidicon camera tube on which the reflected beam from the cornea was focussed. The signal of camera 1 was electronically mixed with that of camera 2 viewing the stimuli on monitor 9 . After suitable 


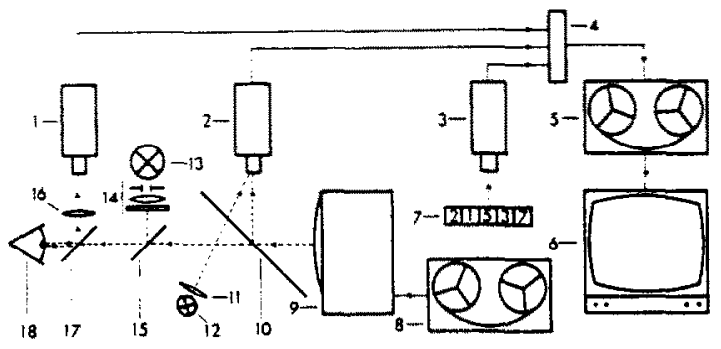

Fig. 4. Set-up for presentation of the stimulus material and for measurement of eye movements by means of the cornea-reflection technique: $1=T V$ camera for recording the i.r. cornea-reflection spot; $2=$ TV camera for simultaneous recording of the stimuli presented: $3=$ TV camera for registration of the field numbers, for timing purposes; $4=$ video mixer; $5=$ video tape recorder for the overlapping registration of the scene presented, the position of the cornea-reflection spot and the field number; $6=$ monitor screen of the experimenter: $7=$ number display, trigered by the vertical synchronisation signal of the TVcameras: $8=$ video tape recorder for presentation of the stimulus material: $9=$ TV monitor for presentation of the stimuli to the observer; $10=$ semi-reflecting mirror; $11=$ lens; 12 = signal light to be controlled by the observer: $13=$ light source for generation of the corneareflection spot; $14=$ diaphragm, i.r. filter and lens; $15=$ semi-reflecting mirror; $16=$ lens: $17=$ semi-reflect ing mirror: $18=$ the observer's eye.

calibration we were able to match both TV signals in such a way that the position of the cornea reflection spot almost coincided with the observer's fixation point. Systematic deviations between both locations remained within $1^{\text {" of visual }}$ angle. the largest deviation occurting at the corners of the $22.3 \times 16.8^{2}$ monitor screen. By means of the obligatory fixations on the display centre, during the rest field presentations in between the stimulus fields, the measurements were corrected every $5 \mathrm{sec}$ for the possible occurrence of drift due to small remnants of head movements. We tried to eliminate these head movements, by using a forehead rest and a bite board with a dental cast of the observer concemed. Moreover much help was obtained from a back-head rest, thanks to which the observer was not required to clench his teeth on the bite board consistently. He could "hang" by his upper jaw and the back of his head, thus preventing lock-jaw.

For identification and timing purposes, the successive TV fields to be recorded were labeled in the lower left corner with a serial number. This was done by focussing camera 3 on the digital L.E.D. display of a pulse counter that was triggered by the vertical synchronisation signal of the TV cameras. The TV system enabled us to sample the eye movements in 20 msec intervals. A push button enabled the observer to indicate the discovery of the target in the stimulus fields. This button controlled a small light signal that became optically mixed with the image from monitor 9 and so further inserted into the eye movement recordings (see Fig. 4).

\section{(2.2) Obserters}

The experimental data to be presented were obtained from the observers TB and FE. Both were experienced observers with adequate vision without spectacles. They had natural teeth, which was important in view of the use of the bite board. for reliable measurement of the eye movements. All experiments reported were repeated by at least one inexperienced observer, being not always the same one, however. Their results were almost similar to the data to be reported.
(2.3) Terminology

$D=$ diameter test disk (ranging from $0.34^{\circ}$ to $0.69^{\circ}$ of visual angle).

$D_{0}=$ diameter background disks $\left(0.55^{\circ}\right.$ of visual angle).

$A=$ area of the display $\left(22.3^{\circ} \times 16.8^{\circ}\right.$ of visual angle).

$L=$ length of eye saccade.

$N=$ number of events.

$n=$ cumulative number.

$P_{c d}=$ cumulative probability of fixation, respectively of discovery.

$P_{d}=$ proportion of discovered targets at a given eccentricity.

$P_{t}=$ proportion of target eye movements for target presentation at a given eccentricity.

$P_{f}=$ proportion of free eye movements for target presentation at a given eccentricity.

$P_{1}=$ single fixation probability of test object discovery.

$P_{\mathrm{Y}}=$ probability of target discovery at the $N$ th fixation.

$P(t)=$ probability of target discovery as a function of time.

$R$ = retinal eccentricity of target presentation.

$\bar{R}_{50}=$ size (average radius) of the conspicuity area at $50 \%$ threshold level

$R^{*}=$ normalized eccentricity $=R / \bar{R}_{30}$

$\rho=$ effective size of the relevant conspicuity area during search.

$t=$ (search) time.

$i$ = average search time.

$T_{\mathrm{fix}}=$ fixation duration, including duration of the corresponding saccade.

$\Delta T_{t}=$ delay time between stimulus onset and target eye movement.

$\Delta T_{f}=$ delay time between stimulus onset and free eye movement.

$\Delta T_{s}=$ delay time between stimulus onset and the manual light-signal response.

\section{(3) CONSPICUITY AREA DETERMINATIONS}

In the experiments to be described in this section, the observer was instructed not to move his eyes. He had to fixate a small continuously visible cross in the centre of the screen and when the stimulus pattern appeared, to indicate with the push-button switch if he discovered the target object. After finishing a complete series of stimulus patterns, in which the same target object appeared in random sequence once on each of the 50 intersections of the imaginary circular grid (Fig. 2a) around the fixation cross, the extent of the corresponding binocular conspicuity area was obtained. For improvement of reliability each series has been displayed 4 times to each of the observers.

As we aimed at relating the conspicuity area results to the search experiments to be described in Sections 5 and 6 , the conspicuity area determinations were performed in the same cornea-reflection set up. This procedure moreover offered the possibility of gaining information about the accuracy of fixation.

\section{(3.1) Experimental results}

Figure 5 gives for both observers the averaged proportion $P_{d}$ of targets discovered, as a function of the eccentricity $R$ of target presentation. The $100 \%$ level in Fig. 5 corresponds to 40 target discoveries, since each stimulus series with 10 target presentations at 

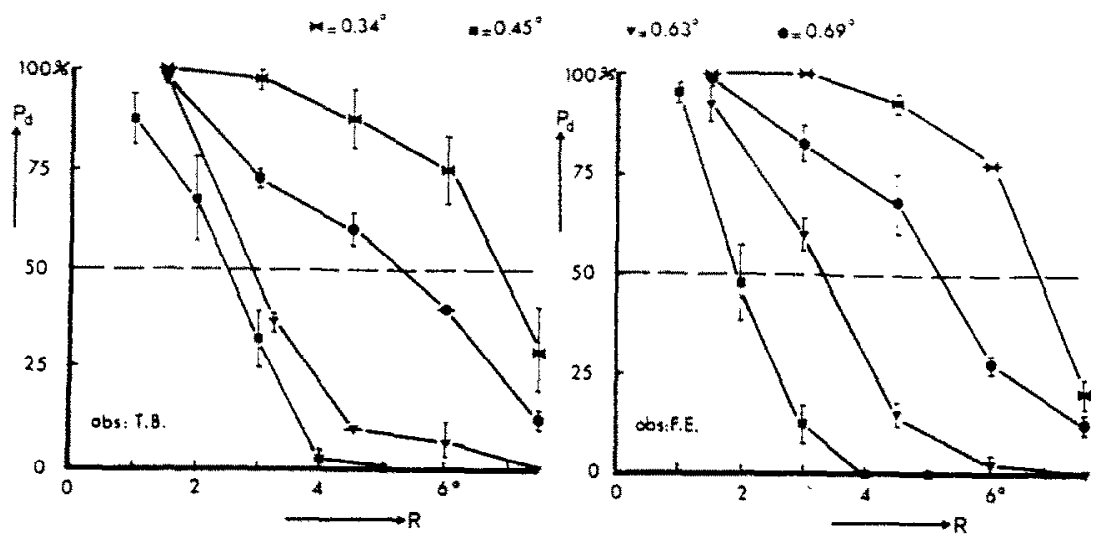

Fig. 5. The proportion $\left(P_{d}\right)$ of discovered targets as a function of the eccentricity $(R)$ of their presentation relative to the central fxation cross. for two observers (TB and FE). The diameter ( $D)$ of the target disk has been taken as parameter. The diameter of the background disks $D_{0}=0.55^{3}$ visual angle. The vertical bars indicate the experimental estimate of the S.E.M. The omission of such a bar at certain data points (e.g. for TB at $R=6^{\circ}$ for $D=0.69^{*}$ ) indicates that the estimated standard error equals zero.

the same eccentricity (Fig. 2 a) has been displayed 4 times.

The eccentricity at which $50 \%$ of the targets, presented in 10 directions, were discovered, has been taken as the size $\left(\bar{R}_{50}\right)$ of the (binocular) conspicuity area. Figure 6 a gives values of $\bar{R}_{50}$, calculated by means of linear regression technique from the relevant data points in Fig. 5. In Fig. 6b these values are plotted against the absolute difference in diameter between the target and the background disks.

\section{(3.2) Discussion}

As indicated in Fig. $6 \mathrm{~b}$, the size $\bar{R}_{50}$ of the binocular conspicuity area increases about linearly with the absolute difference in diameter between target disk and background disks. Taking into account the relatively small range of diameter differences used, this result is qualitatively in line with the data of earlier

\begin{tabular}{|c|cccc|c|}
\hline$D=$ & $0.34^{\circ}$ & $0.45^{\circ}$ & $0.63^{\circ}$ & $0.69^{\circ}$ & observer \\
\hline$F_{50}=$ & $0.8^{\circ}$ & $2.4^{\circ}$ & $3.2^{\circ}$ & $5.0^{\circ}$ & T.8. \\
$F_{50}$ & $0.5^{\circ}$ & $2.0^{\circ}$ & $3.4^{\circ}$ & $5.1^{\circ}$ & F.E. \\
\hline
\end{tabular}

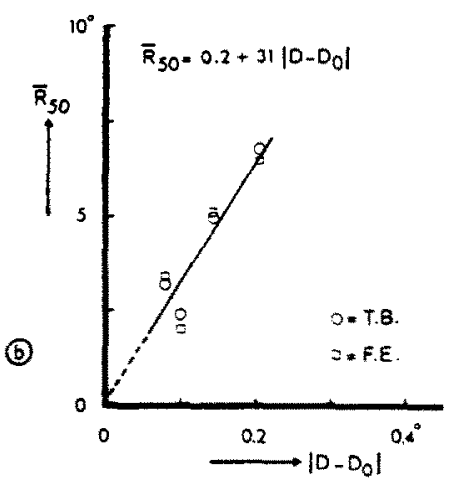

Fig. 6. (a) The size $\left(\bar{R}_{30}\right)$ of the binocular conspicuity area for different target diameters $(D) ; D_{0}=0.55^{\circ}$ visual angle. (b) The size $\left(\bar{R}_{90}\right)$ of the conspicuity area against the absolute difference $|D-D O|$ in diameter between the target and background disks. The relation can be approximated by the indicated linear regression function. monocular conspicuity area determinations (Engel, 1974). There namely over a much larger range of diameter differences, we fitted the data to a logarithmic function of the "contrast" in diameter $\left(\log \left\{\left(D-D_{0}\right) D_{0}\right)\right.$. The data do not quantitatively agree however. probably because of differences in ex. perimental circumstances. For instance, in the earlier experiments the background disks were much larger $\left(D_{0}=3.5^{\circ}\right)$. The other factors that possibly contributed to this discrepancy were the differences in exposure time and in the luminances applied, while in contrast to the earlier monocular presentations the stimuli were now presented binocularly.

Due to the simultaneous measurement of eye movements during which speaking was impossible, the observer had to respond with the signal light only. Therefore we had no direct check on the correctness of the responses obtained. We accepted this shortcoming, since the reproducibility of the results was reasonable; in Fig. 5 the vertical lines through the data points indicate the standard errors of the means. The rather extended transition regions depicted in Fig. 5 mainly result from the generally non-circular shape of the conspicuity areas (see e.g. Engel, 1971).

During the brief $(80 \mathrm{msec}$ ) stimulus exposures of earlier conspicuity area determinations (Engel, 1971, 1974), practically no eye movements occurred. However, during the longer ( $1 \mathrm{sec}$ ) exposures used this time, a small to-and-fro eye movement was frequently observed in the direction of the target discovered. In the following Section 4. we shall go somewhat further into the properties of these small "spontaneous" eye movements, since they depend on the conspicuity of the target used. As mentioned earlier, Section 4 may be passed over in the first reading. its essence being the finding that the occurrence and corresponding delay of these eye movements depended on the target eccentricity and on the size of the corresponding conspicuity area.

\section{(4) SPONTAYEOLS EYE MOVEVIENTS}

Although our observers did their best to maintain fixation on the marked centre of the screen. neverthe- 

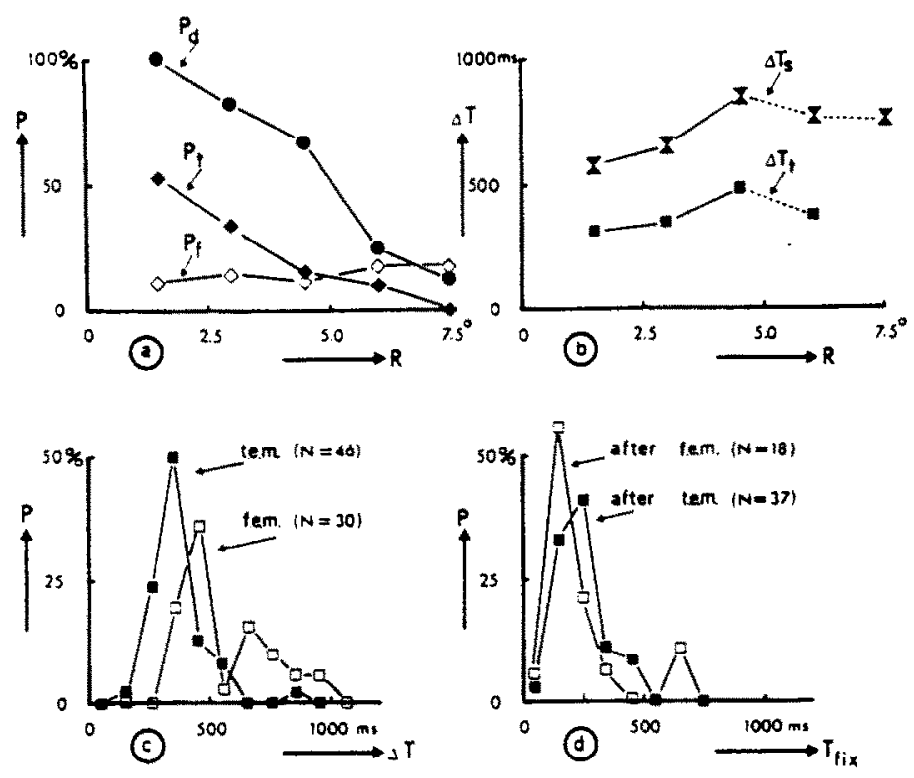

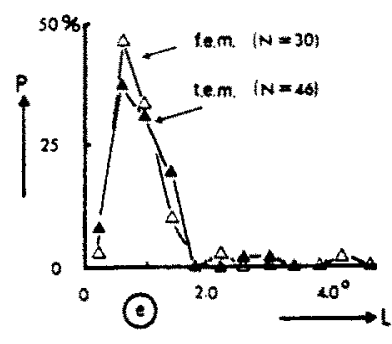

obs: F.E.

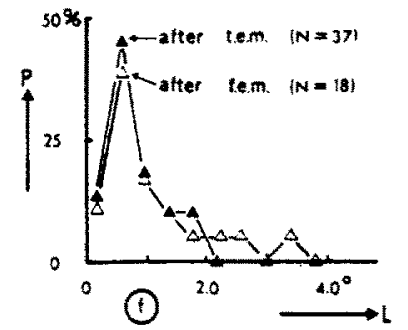

$0=0.69^{\circ}$

Fig. 7. Typical characteristics of the spontaneous eye movements made by $F E$ in the $0.69^{2}$ target situation. (a) Proportion $(P)$ of occurrence of spontaneous eve movements in percentage of the total number $(40)$ of targets, presented at the indicated eccentricity $R$. $P$, concerns target eve movements while $P_{f}$ concerns free eye movements. For comparison purposes, $P_{d}$ the proportion of discovered targets (from Fig. 5) has also been plotted. (b) The delay time $\Delta T_{\text {f }}$ between stimulus onset and target eye movement and the delay time $\Delta T_{s}$ between stimulus onset and the light-signal response of the observer against the retinal eccentricity $(R)$ of target presentation. The results at $R=6^{3}$ and $R=7.5^{\circ}$ visual angle are not very reliable in view of the paucity of events at these eccentricities (see $P_{x}$ and $P_{d}$ in Fig. 7a). (c) Frequency polygons of the delay time before occurrence of a target eye movement (t.e.m.) and before occurrence of a free eye movement (f.e.m.), $N$ indicates the total number of events, (d) frequency polygons of the eccentric fixation duration $\left(T_{\mathrm{fix}}\right)$ after target and free eye movements. (e) frequency polygons of the length $(L)$ of the target and free eye movements away from the centre, and $(f)$ frequency polygons of the saccade lengths $(L)$ towards the centre after target and free eye movements respectively.

less rather frequently a small spontaneous eye movement occurred some $400 \mathrm{msec}$ after onset of the stimulus pattern, mostly in the target direction. Usually this spontaneous saccade was followed about 200 msec later by a second small movement back to the fixation centre. If the first saccade was in the target direction, we called it a "target eye movement", we named it on the other hand a "free eye movement" if it occurred in another direction. The target eye movements, with an average length of about $0.7^{\circ}$ of visual angle, were too short to reach the target. Nearly all target eye movements were followed roughly $300 \mathrm{msec}$ later by the light signal, indicating the discovery of the target.

Most times our observers were unconscious of their spontaneous eye movements. As far as they were aware they felt that they had made a target eye move- ment before they realized it. As a typical example, characteristics of such spontaneous eye movements are given in Fig. 7 for one experimental situation. In view of the newness of this phenomenon, the graphs given in Fig. 7 will be considered more extensively in this section, together with other relevant data.

\section{(4.1) Occurrence}

As a function of target eccentricity Fig. 7a gives the proportion $\left(P_{\ell}\right)$ of target eye movements and the proportion $\left(P_{f}\right)$ of free eye movements that occurred.

The $100 \%$ level corresponds to 40 , this being the number of target presentations at the eccentricity concerned. The eye movements have been classified according to their direction. Movements deviating 
less than $18^{\circ}$ from the true target direction were considered to be "target eye movements". the others were taken to be "free eve movements".

The chosen value of \pm 18 corresponded to the division of the circular grid (Fig. 2a), which facilitated the read-out of the recordings. Moreover, it prevented distortion of our results due to the occurrence of deviations in eye movement direction. which appeared to depend systematically on the direction of target presentation. Movements in the top right or left directions for instance, were frequently rotated somewhat counter clockwise, while downward movements were often slightly rotated clockwise. These systematic changes in direction fit in with the curvatures of saccadic eye movements described by Thomas and $O$ Beirne (1967) as a function of saccadic direction. They suggested that these curvatures, which were also found in our eve movement recordings, are due to a non-simultaneous innervation of the extra-ocular muscles.

Although matching of the comea-reflection spot with the fixation cross was not always perfect, the fuctuations of the eye could be detected relatively easily. The spontaneous eye movements especially deviated in dynamic aspects from the slower movements, e.g. of respiration. The structure of the overlapping stimulus pattern also facilitated the detection of these movements. Repeated read-out indicated that our detection of these eye movements was reliable. A relation appeared to exist between the occurrence of these target-eye movements and the discovery of the target. To illustrate this. the relevant conspicuity
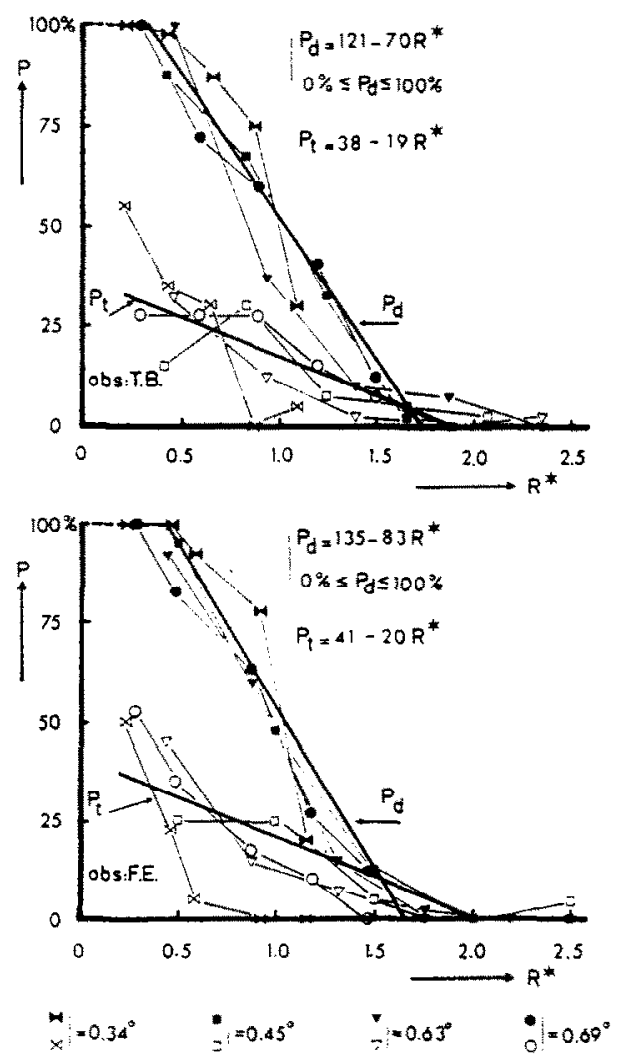

Fig. 8. As a function of the normalized eccentricity $R^{*}$, the proportion of discovered targets $\left(P_{4}\right)$ and the proportion $\left(P_{1}\right)$ of target eye movements. Linear regression lines have been drawn to indicate their relationship. The coefficients of the corresponding equations have been truncated in accordance with their statistical reliability.
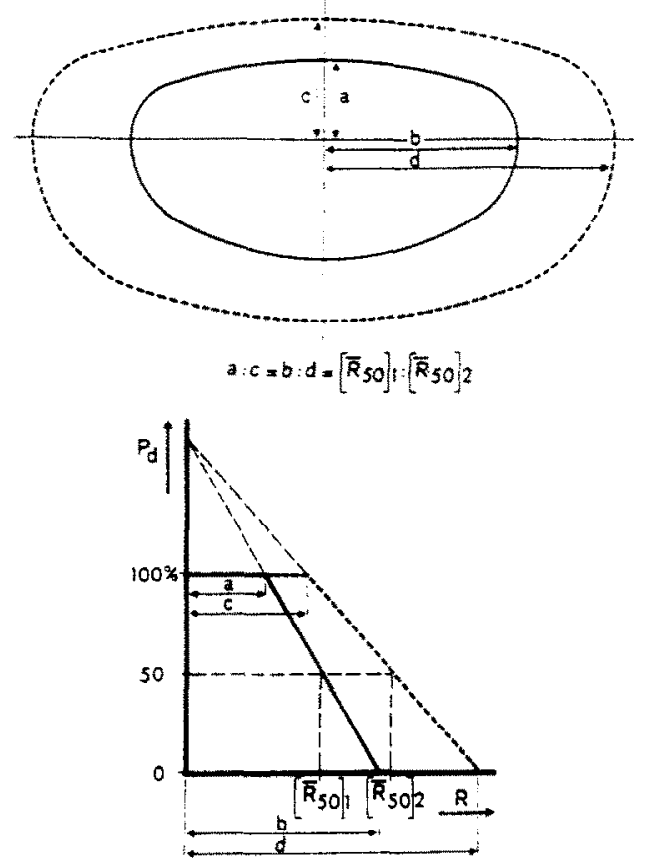

Fig. 9. Assuming that the ratio of the smallest to the largest eccentricity of the conspicuity area remains similar with increase in size $(a: c=b: d)$. see the upper drawing, it follows that the corresponding borders can be approached by straight lines intersecting the $P_{d}$ axis at the same point, see the lower drawing. It implies that these lines can be normalized through $R^{*}=R / \bar{R}_{50}$.

area data from Fig. 5 has been redrawn in Fig. 7a. In fact, in $90 \%$ of the times that such a target eye movement occurred, the signal light switched on some $300 \mathrm{msec}$ later, indicating the conscious discovery of the target object. The relation between $P_{d}$ and $P_{t}$ is more fully apparent in Fig. 8, where we plotted all conspicuity area data, as given in Fig. 5 , as well as the fractions of occurrence of the corresponding target eye movements, against the normalized eccentricity:

$$
R^{*}=R / \bar{R}_{50}
$$

The fractional normalization supplied a better mutual fit of the data for the different test objects than a normalization according to $\left(R-\bar{R}_{50}\right)$. This corroborates the suggestion given in Section 3, para. 2, that the relatively large transition regions in Fig. 5 are mainly due to the non-circular shape of the conspicuity areas. Namely, if we assume an approximatively unchanged shape with increase in size, i.e. a constant ratio of the smallest to the largest threshold eccentricity, it can be shown by means of the similar triangles in Fig. 9, that the transition region increases in proportion to the size of the conspicuity area, so that here a fractional normalization meets our needs. According to a first order approximation, as given by the linear regression lines and the corresponding equations in Fig. 8. these target eye movements occurred in the case of our two observers in about $30-40 \%$ of the times that the test object was discovered.

As to the free eye movements, their proportion of occurrence $\left(P_{f}\right)$ appeared to be rather low and independent of the eccentricity of test object presentation (see Fig. 7a). Perhaps they were related to certain background objects, which were sometimes presented quite close to the fixation centre. We could not find a systematic origin, however, 

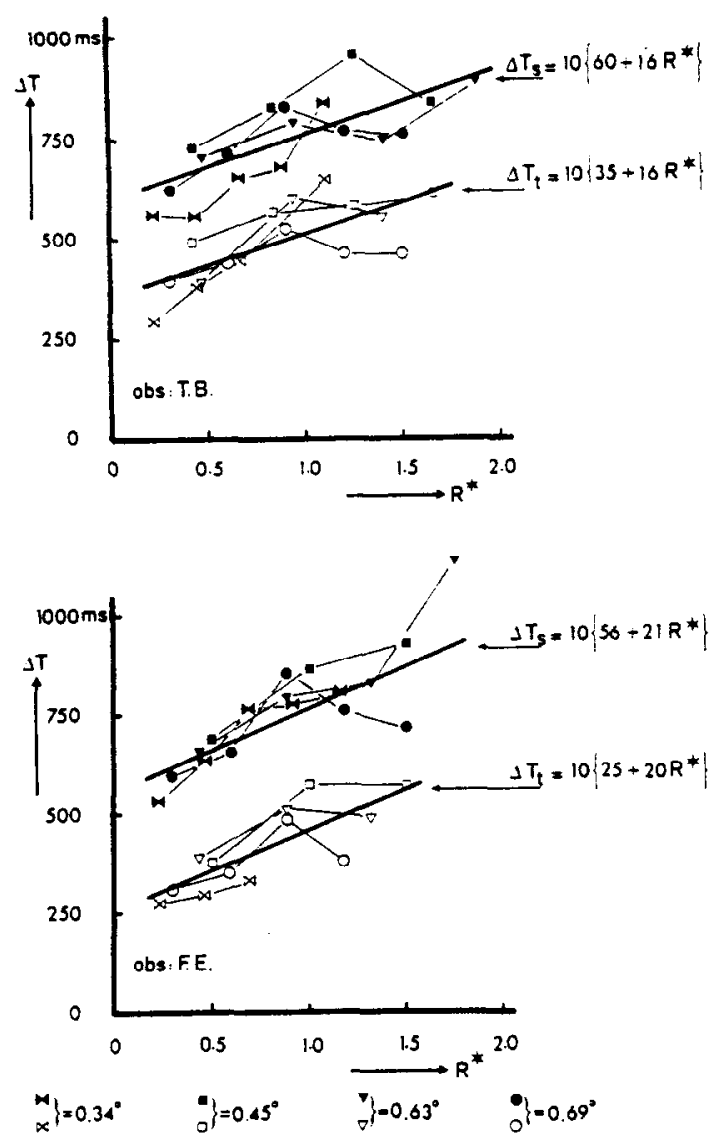

Fig. 10. The delay time $\Delta T_{t}$, before occurrence of a target eye movement, and the delay time $\Delta T_{s}$ before occurrence of the observers response with the light signal, plotted against the normalized eccentricity $R^{*}$. The overall linear regression lines plotted emphasize: (a) the increase in delay with $R^{*}$ and (b) the constant difference between $\Delta T_{s}$ and $\Delta T_{r}$

except that they were related in time to the onset of the stimulus pattern (Fig. 7c)

\section{(4.2) Delays}

In Fig. $7 \mathrm{~b}$ we plotted against target eccentricity $R$, the delay $\Delta T_{t}$ between stimulus onset and target eye movement and the delay $\Delta T_{s}$ between stimulus onset and the light signal response. Both delays increased with $R$, the difference between them being almost constant. In relation to Fig. $7 \mathrm{~b}$ it should be remarked that the indicated delay times at $R=6.0^{\circ}$ and $R=7.5^{\circ}$ of visual angle are less reliable because of the small number of events (see Fig. 7a) over which an average has been taken. Virtually all our delay time data showed the two mentioned tendencies. Moreover, the increase with $R$ appeared to depend on the size $\bar{R}_{\text {so }}$ of the conspicuity area concerned, larger areas giving, on the whole, shorter delay times as well as smaller increases with $R$. These effects could be summarized by plotting them against $R^{*}=R / \bar{R}_{50}$ (Fig. 10). The overall linear regression lines plotted through the data in Fig. 10 stress the increase in delay with $R^{*}$ and the constant difference of $250 \mathrm{msec}$ for TB and $300 \mathrm{msec}$ for FE between $\Delta T_{s}$ and $\Delta T_{t}$.

The results presented needed no further correction for the inherent opto-electronic delay of the TV camera sys- tem, since all three signals (the stimulus onset, $\Delta T_{s}$ and $\Delta T_{s}$ ) appeared to be delayed about equally, viz. the duration of one TV field $(20 \mathrm{msec})$.

It should be noted that the $\Delta T_{s}$ values are not regular reaction times because we did not explicitly ask the observers to control the light signal as fast as possible. However, we do not believe the difference to be large in practice since the experimental set up forced them to react rapidly in order to be in time for the next stimulus presentation.

Two hypotheses are conceivable as to the nearly constant difference in delay time between the onset of a target eye movement and that of the corresponding manual light response signal. The first is that both motor actions are initiated at the level of target recognition, so that the difference in delay would be the result of a difference in transition time. The second is that the target eye movement had been initiated already at the moment that the target triggered selective attention (see also Fig. 19) and that the push-button action started after target recognition. which is supposed to occur later. In view of the relatively large difference in delay. we consider the second hypothesis to be more credible. This would imply that $\Delta T_{t}$ relates to the conspicuity of the target object, as will be later shown to be the case indeed (Fig. 11).

An outstanding aspect of our delay-time data is their relatively large increase with increasing $R^{*}$. For instance, in Fig. 10 for FE. $\Delta T_{t}$ increases about 250 msec in the transition region approximately lying between $R^{*}=0.4$ and $R^{*}=1.6$ (see Fig. 8), which corresponded for $\bar{R}_{50}=2.0^{\circ}$ (observer FE, $D=0.45^{\circ}$ ) to a difference in eccentricity of $2.4^{\circ}$ of visual angle only. Since the conspicuity areas are non-circular in general, even sharper increases in delay time are to be expected for single direction data. The data in Fig. 10 specifically represent results obtained by averaging over 10 directions. The small amount of data available for each direction separately does not allow us, however, to check this point reliably now. Schiepers (1974), who investigated word recognition in eccentric vision found a comparable value, viz. $150 \mathrm{msec} / \mathrm{deg}$ visual angle, for the increase in vocal response latency against eccentricity of word presentation.

The increase in delay time, reported in the literature as a function of the retinal eccentricity for single objects on plain backgrounds are much smaller. Bartz (1962) reported, for instance, for a $30^{\circ}$ difference in eccentricity about $50 \mathrm{msec}$ difference in eye movement

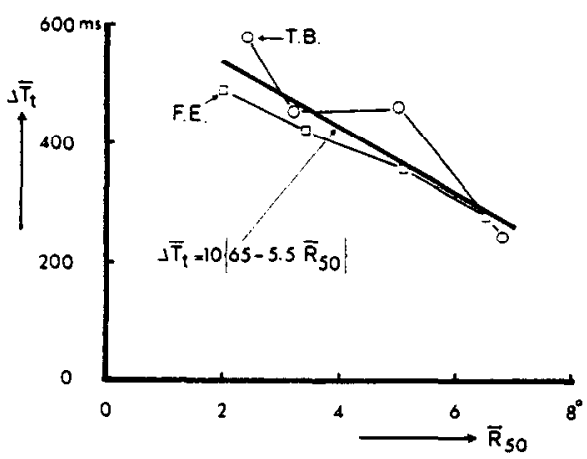

Fig. 11. The arithmetic mean $\left(\Delta \bar{T}_{t}\right)$ of the delay times before occurrence of a target eye movement, against the size $\left(\bar{R}_{50}\right)$ of the corresponding conspicuity area. 
latency, while regular pushbutton reaction times vielded on the average some $30 \mathrm{msec}$ difference for a $30^{\circ}$ difference in eccentricity with respect to the fovea (Rains, 1963: Paine, 1966). The authors used isolated objects with luminance-contrast values well above threshold. In view of the results of our earlier work (Engel. 1971. 1974), it may be assumed that these isolated objects possessed relatively large conspicuity areas, so that their object presentations were of course located within the corresponding conspicuity areas. Our data can then be taken to agree with their results, since the predicted increase in delay time from 0 towards $R^{*}=0.4$, obtainable by extrapolation of the regression lines in Fig. 10, is at most about $80 \mathrm{msec}$. For $6^{2}$-horizontal target steps, as a function of target luminance and contrast. Wheeless, Cohen and Boynton (1967) found the saccadic reaction time to vary from about $450 \mathrm{msec}$ at threshold level to about 250 msec for much higher levels. Their data roughiy correspond to our delay times found for the transition region.

Let us now consider Fig. 7c, where we have plotted separately for target and free eye movements the frequency polygons of the time lapse $\Delta T$ between the stimulus onset and the moment of occurrence of these eye movements. The target eye movements occurred on average earlier than free eye movements. All our results showed this tendency significantly. Moreover, as already touched upon in relation to Fig. 10 , the mean over the transition region obtained $\Delta T_{t}$ values for target eye movements decreased with increasing $\bar{R}_{50}$. In Fig. 11 this is shown by plotting the arithmetic mean $\left(\Delta \bar{T}_{t}\right)$ of that delay against $\widetilde{R}_{50}$. In connection with the How diagram in Section 7, para. 2, we shall there propose an explanation for the decreasing $\Delta T_{3}$ with increasing $\bar{R}_{50}$ and decreasing $R^{*}$.

No significant dependence of the mean delay $\Delta \bar{T}_{f}$ on $\bar{R}_{50}$ was found for the free eye movements. For these movements $\Delta \bar{T}_{f}$ equalled about $0.52 \mathrm{sec}$, which is relatively long compared to the values obtained for target eye movements (Fig. 11).

\section{(4.3) Corrective actions}

Frequency polygons for the off-centre fixation durations $\left(T_{\text {fix }}\right)$, following the target and free eye movements are given separately in Fig. $7 \mathrm{~d}$. The means of these polygons neither differed significantly from each other, nor from the values obtained with the other target objects. For TB the averaged $T_{\mathrm{fix}}$ amounted $0.34 \mathrm{sec}$, for $F E$ this was $0.21 \mathrm{sec}$. These values are in general smaller than the $\Delta T_{t}$ values mentioned in Section 4, para. 2, which is perhaps a result of foreknowledge with respect to the location of the display centre. Another interpretation is that the target eye movements are the result of a difference in time of arrival of the command for a spontaneous target eye movement and a reaction command both for interrupting and correcting the undesired movement. The latter interpretation seems supported to some extent by the fact that these saccades from and towards the fixation centre were relatively small and that their length distributions were almost similar for all test objects used, for target as well as for free eye movements.

As an illustration of these similarities, frequency polygons of the length distributions for one target size and one observer are given for the saccades from the fixation centre away (Fig. 7 ) and for the saccades back to this centre (Fig. 7f). The averaged median value of the overall distributions amounted to 0.8 : of visual angle for $T B$ and $0.6^{\circ}$ for $F E$.

\section{(5) SEARCH TIME}

In contrast to the conspicuity area experiments described in Section 3. the observer was this time allowed to move his eves during the stimulus pattern presentations which now lasted 4 sec each. Only during the $1-\mathrm{sec}$ rest fields, which separated the subsequent stimulus patterns. he had to tixate the centre of the screen for calibration purpose. When he discovered the relevant test object he had to indicate this by means of the light signal. The stimulus patterns always contained two different test objects, one larger and the other smaller than the 0.55 background disks (Fig. 1). In this way two different series of stimulus patterns were made available on video tape. see Sec. tion 2. para. 1. One series had a relatively conspi. cuous larger test object $\left(D=0.69^{\circ}\right)$ and an inconspicuous smaller one $(D=0.45)$ while the other series had an inconspicuous larger object $(D=0.63)$ and a relatively conspicuous smaller test object $(D=0.34)$. In four subsequent sessions the observers were instructed to search in turn for one of these four test objects, the target and to avoid fxation on the other test object irrelevant to the present search task, the non-target. The discovery of the target was taken for granted when both the light signal appeared and the observer fixated the test object. the latter being an almost spontaneous reaction when he indeed discovered it.

\section{1) Results and discussion}

Figure 12 gives for both observers, the cumulative polygons of the number $(n)$ of targets discovered against search time $(t)$. i.e. the time elapsed between the stimulus onset and the moment of target fixation. The four experimental functions correspond to the four different targets used in the successive sessions.

With regard to the theoretical description of the experimental data in Fig. 12. We shall now consider two somewhat extreme possibilities of the way our observers could have performed their search tasks.

The first is the assumption of "systematic search". which is in a way comparable to sampling without replacement. It means that the observer avoids reexamination of areas already searched over. In an ideal search pattern of this type there is no overlap of the conspicuity areas, thought to be centred around the locations fixated. As a consequence the probability $\left(P_{Y}\right)$ of discovering the target at the $N$ th fixation equals the single fixation probability $\left(P_{1}\right)$ of target discovery, so the ratio of conspicuity area over display area; given as a formula:

$$
P_{x}=P_{1}
$$

for $1 \leq N \leq 1 P_{1}$. Thus, required search time will be finite here and the cumulative probability $\left(P_{c d}\right)$ of target discovery will be described by a linear function of search time $(t)$ :

hor

$$
P_{i d}(l)=P_{i} \cdot t \bar{T}_{f i x}
$$

$$
\bar{T}_{\text {rix }} \leq t \leq \bar{T}_{\text {iix }} P_{1} \text {. }
$$



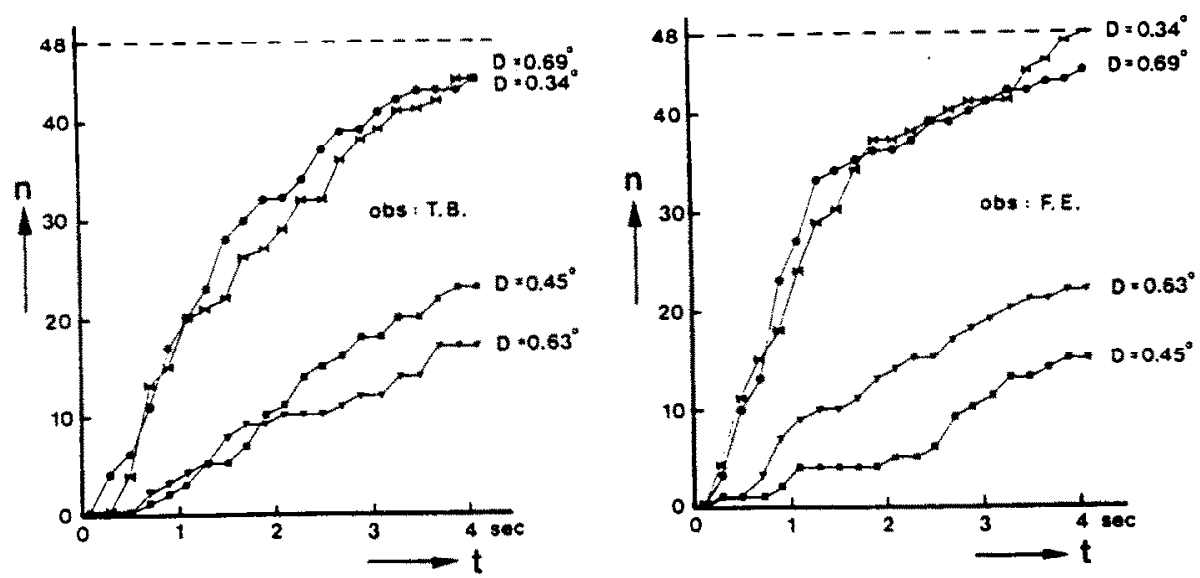

Fig. 12. For the observers TB and FE and the four different targets (with diameter $D$ ), the cumulative polygons of the number $(n)$ of targets discovered against search time $(t)$. The dotted line at $n=48$ indicates the maximum number of targets, that could be discovered in a single series of stimulus patterns.

In this formula $t / T_{\text {fix }}$ corresponds to the number of fixations in $t$ sec of search.

The second somewhat extreme possibility is the assumption of "non-systematic search", i.e. search by means of independent fixation positions over the display. Here the observer forgets as it were his previous fixation locations. In that case the probability of target discovery at the $N$ th fixation decreases according to:

$$
P_{\mathrm{v}}=P_{1}\left(1-P_{1}\right)^{x-1}
$$

The cumulative probability of discovering the target as a function of time then becomes:

$$
P_{s d}(t)=1-\left(1-P_{i}\right)^{r / \bar{T}_{i x}}=1-\mathrm{e}^{-a t}
$$

with

$$
a=\left(-1 / \bar{T}_{\mathrm{fix}}\right) \ln \left(1-P_{1}\right)
$$

for

$$
t \geq \bar{T}_{\text {fix }}
$$

The functions (3) and (5) ought to have the same initial slope. since for $t=\bar{T}_{\text {fix }}, P_{\text {cd }}$ equals $P_{1}$ in both cases.

For comparison Fig. 13 gives the functions (3) and (5), fitted to one of the experimental curves of Fig. 12.

Apparently our experimental data are approximated better by the assumption of non-systematic search, corresponding to a description by means of equation (5). This finding has been corroborated by the results of others (Krendel and Wodinsky, 1960; Bloomfield, 1972). Also our further experimental cumulative distribution data were described reasonably well by exponential functions. The matching was done by applying linear regression calculations to the experimental data, which have been plotted for that purpose in Fig. 14 on a semi-logarithmic scale in accordance with:

$$
1-\frac{n}{48}=1-P_{c t}=\mathrm{e}^{-a t}
$$

Knowing the mean number of fixations/sec $\left(1 / T_{\text {fix }}\right)$ during search, $P_{1}$ values could be estimated by means of equations (6) and (7) from the slopes of these regression lines. (Mathematically estimating $P_{1}$ from the non-cumulative distributions would be less convenient.) Since the successive target locations in a stimulus series were homogeneously distributed over the display area (Fig. 2b). the effective size $\rho$ of the conspicuity area during search, assumed to be circular, followed from

$$
P_{1}=\frac{\pi \rho^{2}}{A} \text {. }
$$

In this formula $A$ stands for the area of the display.

In calculating the regression lines in Fig. 14 we assumed $P_{c d}=0$ for $0 \leq t \leq 0.2 \mathrm{sec}$, since the minimum time needed before discovery of the target and the accompanying saccade towards it, required at least some $200 \mathrm{msec}$ (see Fig. $7 \mathrm{c}$ in relation to this). The precise value chosen for this delay is, however, not very critical with regard to the $P_{1}$ values derived from the experimental data.

Let us now compare the sizes $\bar{R}_{50}$ of the conspicuity areas as obtained by means of single-fixation exposures (Section 3), with the effective sizes, $\rho$, determined by means of the cumulative probabilities of target discovery. As can be noted from Fig. 15, the

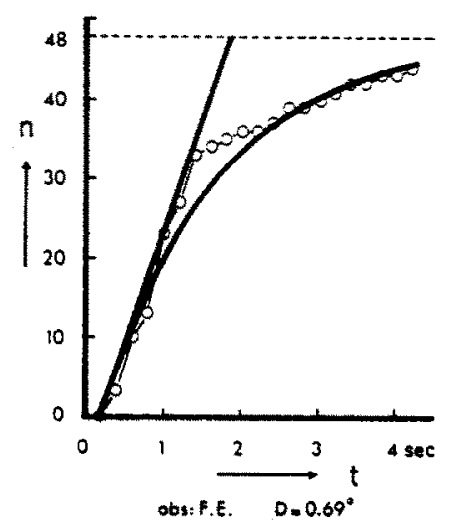

Fig. 13. One of the experimental functions given in Fig. 12 (FE, $D=0.69^{\circ}$ ) approximated both, by a linear function of search time implying the assumption of systematic search, and by an exponential function of search time implying the assumption of non-systematic search. 

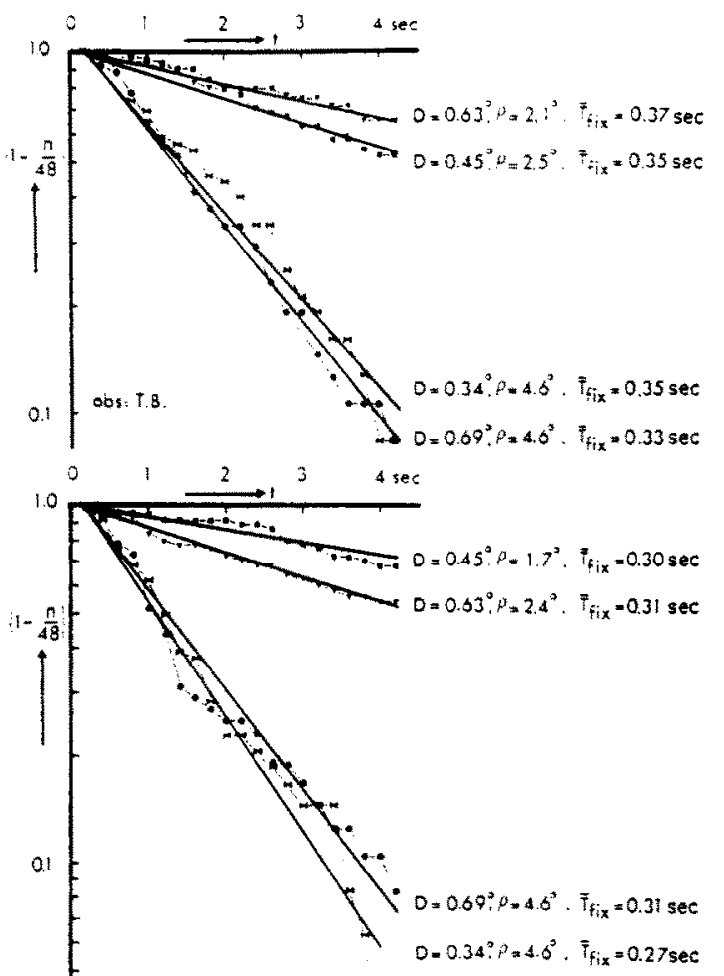

02

Fig. 14. The cumulative number $(n)$ of target objects discovered as a function of time (t). ploted according to equation (7) on a semi-logarithmic scale. The effective size $\rho$ of the conspicuity area during search can be derived via equations (7), (6) and (8) from the slope of the relevant linear regression line.

regression coefficient of $\rho$ on $\bar{R}_{30}$ is smaller than 1 ; in fact the value calculated over the data of the two observers amounted to 0.67 , the correlation coefficient being 0.93. A larger regression coefficient $(0.8) \mathrm{can}$ be obtained indeed by forcing the regression line through the origin.

In formula (8) we assumed the conspicuity areas to be circular. However, in reality the conspicuity

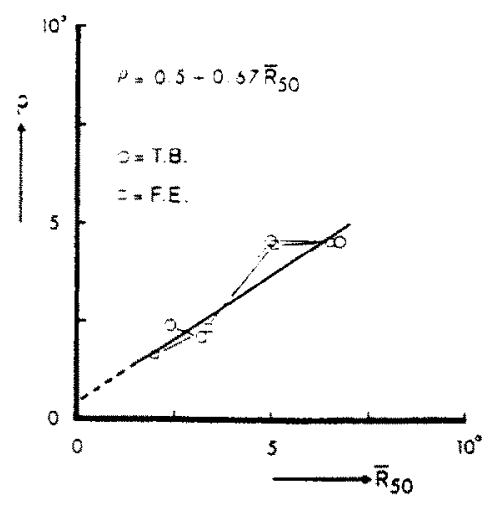

Fig. 15. The relationship between the sizes $\left(\bar{R}_{50}\right)$ of the conspicuity areas, obtained through single fixation stimulus exposures and the effective sizes $(\rho)$ during search. determined from the cumulative probabilities of target discovery.

areas are non-circular in general. Therefore slightly larger values for the average eccentricity, $\rho$. of the area border will be obtained for the same area, but different in shape, if allowance is made for this fact. Further possible reasons for $\rho$ found to be smaller than $\bar{R}_{50}$ will be mentioned in the general discussion (Section 7, para. 1).

Finally, $\bar{T}_{\mathrm{fix}}$ showed no significant correlation with $\bar{R}_{50}$ (see Fig. 14). The overall value of $\bar{T}_{\mathrm{fix}}$ amounted to $0.35 \mathrm{sec}$ for $\mathrm{TB}$ and to $0.29 \mathrm{sec}$ for $\mathrm{FE}$

\section{(6) SPONTAYEOLS FIXATIONS}

During search for the target, there appeared to be a tendency for fixation on the, to the search task irrelevant, non-target in the stimulus pattern. Figure 16 gives for both observers the cumulative number $(n)$ of non-target fixations against their moment $(t)$ of occurrence, as determined from the eye movement records.

By means of the procedure used in Section 5 , the cumulative data of the "spontaneous fixations" were converted into corresponding $\rho$-values. Together with the cumulative fixation data of the four non-targets used, these values are given in Fig. 17. The data are corrected here for the termination of search after tar-
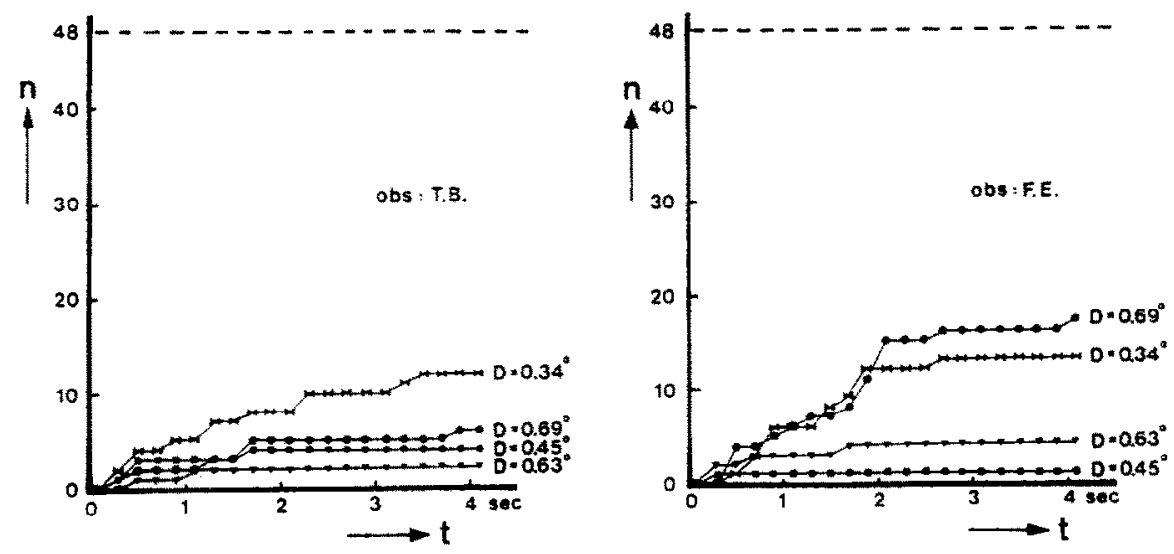

Fig. 16. The cumulative polygons of the number $(n)$ of spontaneous non-target fixations during search for the target. for the observers TB and FE. against their moment $(t)$ of occurrence. 

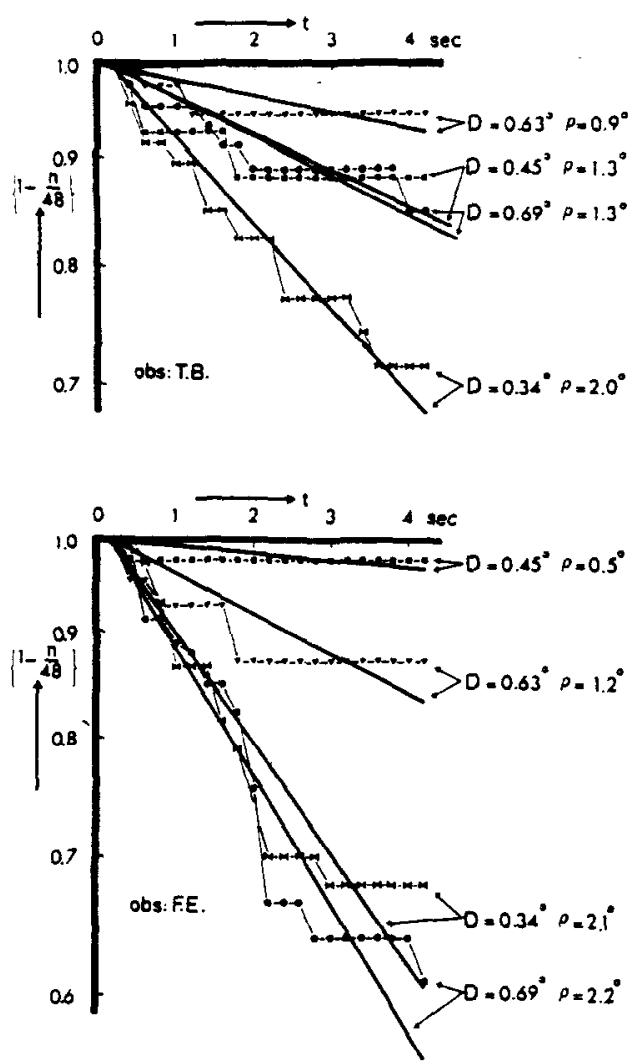

Fig. 17. The cumulative number (n) of fixations on the non-targets irrelevant to the search task as a function of time ( $t$ ). plotted according to formula (7) as linear functions, together with the corresponding $\rho$-values.

get discovery. In view of the amount of non-linearity of our cornea-reflection method in supplying the locations of fixation over the display (at most about $1^{\circ}$ visual angle), we assumed that an object was fixated when the cornea-reflection spot appeared within $1^{\circ}$ visual angle from its centre after we corrected for drift with respect to the fixation on the centre of the previous rest field. Therefore, on the assumption of a random distribution of the fixation points over the display, $\rho=1^{\circ}$ corresponds to test object fixation by accident.

From the results shown in Fig. 18, underlined by other observer's similar results, it may be concluded that although it was the task of the observer to avoid fixation on the irrelevant non-target in the stimulus patterns they did not succeed too well. Most $\rho$-values are specifically larger than $1^{\circ}$ of visual angle, which indicates that these non-targets were fixated more often than corresponds to a random distribution of fixation spots over the display.

Moreover, it is found from the $\rho$-values given in Fig. 18 that the probability of fixation on the non-targets is approximatively proportional to the squared size $\left(\bar{R}_{50}\right)$ of the corresponding conspicuity area $\left(\rho \simeq 0.3 \bar{R}_{s 0}\right)$. The overall correlation coefficient between $\rho$ and $\bar{R}_{50}$ was 0.86 this time. In consequence the instruction not to fixate the non-targets instead of searching for them, resulted in a decrease of the regression coefficient of $\rho$ on $\bar{R}_{50}$ by a factor of $0.28 / 0.67$.

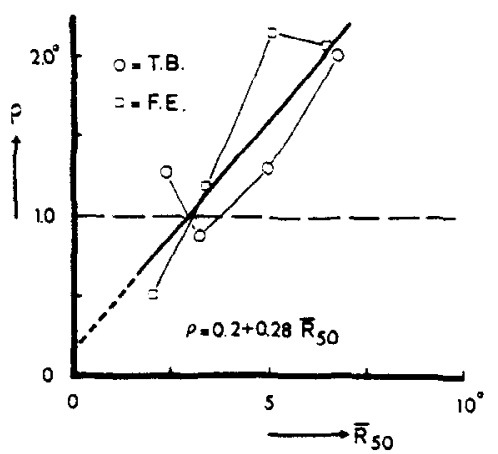

Fig. 18. The effective sizes $\rho$ of the conspicuity areas for the non-targets, which are in proportion to their probability of fixation, against $\bar{R}_{50}$, the size of the corresponding conspicuity area. The dotted line indicates the $\rho$-level that corresponds to test object fixation by accident.

\section{(7) GENERAL DISCLSSION}

From the experimental data presented two different relationships arose in the main. First there is the demonstrated connection between conspicuity area and the probability of target discovery against search time (Sections 3 and 5) and second, the relation between conspicuity and involuntary eye movements (Sections 4 and 6). In the following sections we shall elaborate both points somewhat further.

\section{(7.1) Conspicuity area and search time}

There is agreement in the literature concerning the possibility of describing the cumulative fraction of target discoveries against search time by an exponential function (Krendel and Wodinsky, 1960; Bloomfield, 1972). Accordingly formula (5) has been also suggested by these authors as applying to their data. implying the introduction of a hypothetical factor $P_{1}$, the single-fixation chance of discovery. Now, by means of the conspicuity area concept and the experiments described, we succeeded in verifying the suggested formula experimentally, thereby relating the size of the conspicuity area to the probability of target discovery against search time.

However, for derivation of formula (5). the assumption of independent fixation position has been made, while it is known that the subsequent fixation positions during search are more or less related. Williams (1966) suggested therefore a somewhat subtler approach by assuming during search a repeated scanning of the display by dependent fixation positions. In relation to this it should be noted that it is probably only due to statistical deviation that the data in Fig. 13 can also be approximated by two successive linear functions. This follows from inspection of Fig. 14 , where these results are presented together with the other experimental data. Actually all authors assume a random and consequently homogeneous distribution of fixation points over the display, which is not necessarily the case however (Brandt, 1940: Enoch, 1959). We have not checked on this requirement thoroughly in our results. A non-homogeneous distribution, e.g. with a lower fixation density in the display corners, would yield however a smaller asymptotic value for $P_{c d}$ and so a smaller effective size $(\rho)$ of the conspicuity area. This then may be 
a second reason, besides the minor one already given in Section 5. para. I on the influence of the assumption of a circular conspicuity area, for $\rho$ to be about $70^{\circ}$ of of $\bar{R}_{50}$.

In relation to this deficiency it should also be noted that the conspicuity areas were determined by presenting the stimulus fields in between non-structured rest fields. This in contrast to the stimuli coming in during the successive fixations in regular search. Since it is known that structured stimuli succeeding each other in time may interfere with each other through backward and forward masking. it is not excluded that smaller conspicuity areas would be obtained if structured rest field were used.

In view of all these factors, that possibly improve the regression coefficient of $\rho$ on $\bar{R}_{50}$, it is not of relevance to consider here the influence on this relation of the choice of the threshold level $150 \%$, see Fig. 5) used for determination of the sizes of the conspicuity areas.

From the nearly unchanged averaged durations of fixation $\left(\bar{T}_{\text {fix }}\right)$ during search for the different targets, as given in Fig. 14, it can be concluded that the observers did not adapt their fixation rate to the diffculty of the search task, at least not in a way that was statistically significant. A similar conclusion was obtained by Gordon (1969) for letter search through printed lists of varying complexity. The averaged fixation duration amounted to $0.35 \mathrm{sec}$ for TB and 0.29 $\mathrm{sec}$ for FE.

Since non-systematic search is comparable to sampling with replacement out of a bimodal set, an estimate of $P_{1}$ and consequently of $\rho$ can also be obtained by determination of the ratio of the total number of times the relevant test object was discovered over the total number of fixations made. The values for $\rho$ obtained in that way differed for targets at most $0.1^{2}$ visual angle from the values obtained via required search time (Fig. 14), and at most $0.3^{3}$ visual angle from the $\rho$-values obtained in that way for non-targets (Fig. 17). This result is in line with the statement made above, that $\bar{T}_{\mathrm{fix}}$ did not vary significantly with the difficulty of the search task.

It is interesting to note that Howarth and Bloomfield (1969) found the averaged search time $(\bar{t})$ to be inversely proportional to the squared difference in diameter between target disk and background disks. Our results corroborate their finding since it appears from the data given in Fig. 6 , that $\bar{R}_{50}$ is about proportional to the difference in diameter.

In relation to the exponential function of search time given by formula (5), it can be shown specifically that the following applies for the averaged search time (i):

$$
i=\int_{0}^{\infty} t \cdot P(t) \mathrm{d} t=\int_{0}^{\infty} t \cdot a \mathrm{e}^{-a t} \mathrm{~d} t=1 / a .
$$

Since

$$
\begin{aligned}
& a=-\left\{\ln \left(1-P_{1}\right)\right\} / \bar{T}_{\mathrm{fix}}[\text { see }(6)], \\
& \bar{t}=\frac{-\bar{T}_{\mathrm{fix}}}{\left(-P_{1}-P_{1}^{2} / 2-P_{1}^{3} / 3 \ldots\right)}
\end{aligned}
$$

and since $P_{1} \ll 1$,

$$
\bar{t} \approx \frac{T_{\mathrm{fix}}}{P_{1}} .
$$

Since

$$
\begin{aligned}
& P_{1}-\pi\left(\bar{R}_{50}\right)^{2} \text { and } \bar{R}_{50}-\left(D-D_{0}\right)(\text { Fig. } 6) \\
& P_{1}-\left(D-D_{0}\right)^{2}
\end{aligned}
$$

so that

$$
\bar{i}-\frac{1}{\left(D-D_{0}\right)^{2}}
$$

It should be noted however, that for larger conspicuity areas the linear proportionality as given in Fig. 6 probably does not apply (Engel, 1974).

\section{(7.2) Conspicuity area and spontaneous eve motements}

In Sections 4 and 6 we have demonstrated the influence of visual conspicuity, on the occurrence of small spontaneous eye movements during obligatory fixation of the display centre and on involuntary fxations during search, respectively.

In earlier work (Engel, 1971) it was found to be helpful to divide the factors controlling selective attention into subject and object factors, or in the terms of Fechner (1860) into voluntary and involuntary determiners of attention. We then considered visual conspicuity to be an involuntary determiner of attention. Now that we are studying selection by way of eye movements, we shall distinguish in a similar way voluntary and involuntary determinants of eye movements. In Fig. 19 we have tried to record our present ideas about these two subsequent selective actions in the visual system, in line with a flow diagram given earlier (Engel, 1971).

At the first stage in Fig. 19, there is a spatial selection by eye movements on the visual stimuli presented, the output being a signal flow limited by eccentric vision. Correspondingly, it is assumed that the representation of objects through activity in the corresponding information channels decreases with retinal eccentricity, the foveal signals being relatively emphasized. In Fig. 19 this has been indicated by the thickness of the arrows. In the following stage of feature extraction, conspicuity arises from mutual inhibitory interactions between units for identical features (Engel, 1974). Irregularities in the stimulus pattern, such as for instance our test objects deviating from the background, will then automatically yield a relatively increased activity of the corresponding feature channels. This then will act upon selective attention, in line with proposals of Deutsch and Deutsch (1963) on the functioning of this mechanism, making the relevant information available for recognition and for a possible further response. The involuntary control signal for the eye movements, containing information about direction and eccentricity of the relevant object is thought to be drawn from the signals after selective attention. (The alternative possibility, tapping this signal of before selective attention. would require an additional selector for separation of the most conspicuous signal. For the moment a decisive answer on this point seems hard to give experimentally.) The involuntary controls are thought to be suppressible by voluntary controls. Our earlier attention area experiments (Engel, 1971), in which the observer had to direct his attention towards a position eccentric from the obligatory fixation spot, indicated that selective attention could be uncoupled 


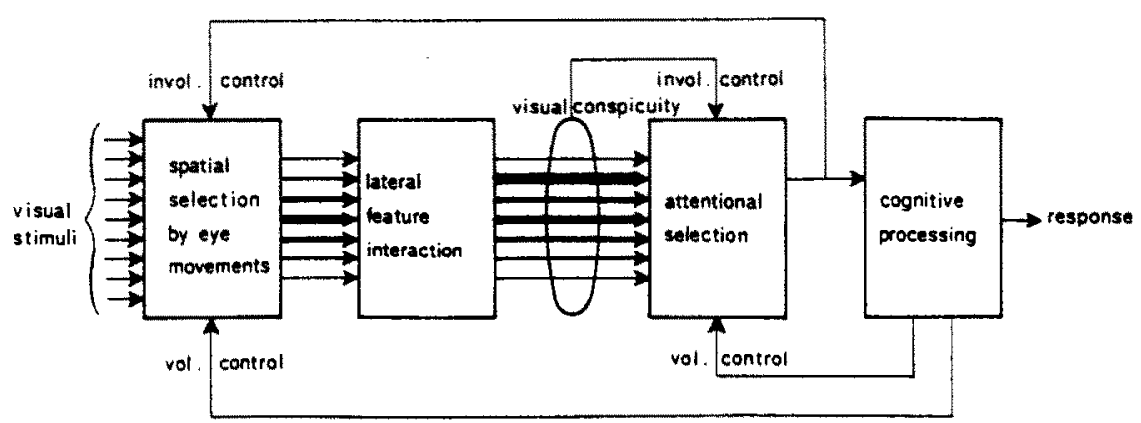

Fig. 19. A tentative diagram of selective data reduction in the visual system through eye movements and selective attention. Visual conspicuity, represented by relatively increased activity of certain information channels, caused particularly by lateral interferences among similar feature channels at the visibility stage, is considered to exercise involuntary control on selective attention and after that on eye movements. These involuntary controls are thought to be counteracted by voluntary controls. Two separate connections for voluntary control have been drawn from the stage of cognitive processing, since it was found from earlier experiments (Engel, 1971) that selective attention could be uncoupled to a certain extent from the line of sight by voluntary act.

from the line of sight by voluntary control. It is for that reason that we have drawn two separate connections from the last box in our diagram, which represents further cognitive processing, namely one for voluntary control of the eye movements and one for voluntary control of selective attention. The experimental results of Kaufman and Richards (1969) also agree with this distinction. They compared the points to which a naive observer believes his eyes are directed and those to which the eyes are in fact oriented.

Let us, in the light of Fig. 19 now consider the spontaneous eye movements described in Section 4. Their occurrence, as well as the delay time $\left(\Delta T_{t}\right)$ before their occurrence, depended on the conspicuity of the target, namely on the size of the conspicuity area and on the eccentricity of presentation both (Figs. 8, 10 and 11). This result fits in with the assumptions made in relation to Fig. 19, of a decreasing activity of the information channels with eccentricity and an activity increasing with conspicuity. Also the experimental results of Levy-Schoen (1969b, 1974), who observed that the nearest of two identical and simultaneously presented stimuli was generally fixated first, corroborate these assumptions. We then need to assume with respect to the delay times, that greater activation leads to shorter delay before directing of attention.

To understand the search time results (Section 5) and the accompanying involuntary fixations on the non-targets (Section 6), we assume that in the absence of critical features such as the test objects, irregularities in the background pattern, edges of the display etc., the eyes under global voluntary control show a quasi random search behaviour. This behaviour is characterized by saccades of a certain length and duration of fixation, both being mainly determined by display size (Enoch, 1959) and perhaps by background complexity. This may account for the overall random fixation positions during search and the practically unchanged averaged fixation duration $\left(\bar{T}_{\text {fix }}\right)$ with changing conspicuity of the target object. In reading, also, there is the suggestion of a rather autonomous motor programme for the eye saccades. Bouma and De Voogd (1974) concluded namely that only the average proceeding of the eyes over the text needs global control by text recognition.

When some critical feature calls upon attention, such as the non-target in our stimulus patterns, an eye movement will be initiated towards it. Only if the required additional decision: "target/non-target", to be taken by the cognitive stage, is performed last enough, could the tendency of fixating the irrelevant test object be suppressed by voluntary control. In view of the results given in Fig. 18 this occurred to a certain extent, resulting in a relatively decreased effective size $(\rho)$ of the conspicuity area for the nontarget compared to the size obtained when this object was the target object. Since no extra visual input is involved here, the time interval between onset of the voluntary cancellation and the occurrence of the saccade must be larger than the roughly $100 \mathrm{msec}$ refractory period preceding a saccade, in which observers are unable to react directly to a second target displacement (see e.g. Komoda et al., 1973; Levy-Schoen. 1969b).

In relation to this it is interesting to note that sometimes a substantial time gap was involved in our search experiments between the intake of target location and the moment of actual performance of the saccade towards the target. That is to say, it happened now and then that after a fixation by accident within the conspicuity area around the target, viz. after a large saccade, there first occurred a relatively large saccade away from the target, presumably under voluntary control, after which the eye returned in one or two jumps, the additional second jump back being a "corrective" saccade. The signal light then appeared afterwards with the usual delay. [For more information on these interesting smaller corrective saccades, which also occur in the absence of visual feedback, see e.g. Weber and Daroff. (1972)]. Sometimes the effect also occurred after offset of the search pattern, making it acceptable that the observer used the information on target location, obtained just before cessation of the stimulus pattern during the first accidental fixation near the target object. This also points to the existence of some accurate internal representation of target location which remains available for a period of at least 2 or 3 saccades. 


\section{(8) CONCLLSLONS}

(1) By assuming a random distribution of fixation positions over the display area during search, we were able to relate experimentally the cumulative probability of target discovery against search time with the size of the conspicuity area concerned, the visual field in which the target can be discovered in a single fixation. As was derived from the search time data, the effective sizes of the conspicuity areas during search were found to be about $30 \%$ smaller than the conspicuity areas determined by means of single tachistoscopic presentations.

(2) During search, non-targets added to the stimulus pattern were found to be involuntarily fixated in proportion to their conspicuity area. In this case the instruction not to fixate the non-targets resulted in an decrease, about $60^{\circ}$, of the effective size of the conspicuity area during search.

(3) During direct determination of the conspicuity areas, requiring strict fixation on the display centre, small to-and-fro eye movements of about $0.7^{\circ}$ visual angle in length occurred nevertheless in the direction of the target object discovered. Their occurrence as well as their delay with respect to stimulus onset depended on the size of the conspicuity area and on the eccentricity of presentation (Figs. 8, 10 and 11 ). These delays increased by about $200 \mathrm{msec}$ over the transition region of the conspicuity area concerned. There existed a constant difference of about $300 \mathrm{msec}$ between the occurrence of these eve movements and the manual recognition response of the observer.

(4) The obtained results were interpreted in terms of a tentative flow diagram of selective information reduction in the visual system (Fig. 19). Visual conspicuity has been taken in relation to this to be an external determiner of both selective attention and eye movements.

(5) The experiments described emphatically demonstrate the usefuiness of the conspicuity area as a concept for research on visual selection.

Acknowledgements-I wish to express my gratitude to Mr. T. M. Bos for his assistance in the experiments, to Dr. J. A. J. Roufs for stimulating discussions on the statistical aspects of this work and to Dr. H. Bouma and Prof. Dr. J. F. Schouten for their critical reading of the manuscript.

\section{REFERENCES}

Bartz A. E. (1962) Eye movement latency, duration and response time as a function of angular displacement. $J$. exp. Psychol. 64, 318-324.

Bloomfield J. R. (1972) Visual search in complex fields: size differences between target disc and surrounding discs. Hum. Factors 14, 139-148.

Bouma H. and De Voogd A. H. (1974) On the control of eye saccades in reading. Vision Res. 14, 273-284.
Brandt H. F. (1940) Ocular patterns and their psychological implications. Am. J. Pivchol. 53. 260-268.

Deutsch J. A. and Deutsch D. (1963) Attention: some theoretical considerations. Psychol. Ret. 70, 80-90.

Engel F. L. (1971) Visual conspicuity, directed attention and retinal locus. Vision Res. 11, 563-576.

Engel F. L. (1974) Visual conspicuity and selective background interference in eccentric vision. lision Res. 14, $459-471$.

Enoch J. M. (1959) Effect of the size of a complex display upon visual search. J. opt. Soc. Am. 49, 280-286.

Fechner G. T. (1860) Ceber timige Verhältnisse des Binoctllaren Sehens. pp. 392-408. Hirzel. Leipzig.

Gordon I. E. (1969) Eye movements during search through printed lists. Percept. Mor. Skills 29, 683-686.

Howarth C. I. and Bloomfield J. R. (1969) A rational equation for predicting search times in simple inspection tasks. Psychon. Sci. 17, 225-226.

Jeannerod M.. Gérin P. and Pernier J. (1968) Déplacements et fixations du regard dans lexporation libre d'une scène visuelle. Vision Res. 8, 81-97.

Kaufman L. and Richards W. (1969) Spontaneous fixation tendencies for visual forms. Percept. Psychophys. 5, $85-88$.

Komoda M. K., Festinger L.. Phillips L. J., Duckman R. H. and Young R. A. (1973) Some observations concerning saccadic eye movements. Vision Res. 13, 1009-1020.

Krendel E. S. and Wodinsky J. (1960) Search in an unstructured visual field. J. opt. Soc. Am. 50, 562-568.

Lévy-Schoen A. (1969a) L'étude des Moutements Oculaires, p. 179. Dunod. Paris.

Lèvy-Schoen A. (1969b) Determination et latence de la réponse oculo-motrice a deux stimulus simultanés ou successifs selon leur excentricité relative. Année psychol. 69. 373-39?

Lévy-Schoen A. (1974) Le champ d'activité du regard: données expérimentales. Année psychol. 74, 43-66.

Mackworth J. F. and Mackworth N. H. (1958) Eye fixations recorded on changing visual scenes by the television eye-marker. $J$. opt. Soc. $\mathrm{Am}$. 48, 439-445.

Noton D. and Stark L. (1971) Scanpaths in saccadic eye movements while viewing and recognizing patterns. lision Res. 11, 929-94?

Payne W. H. (1966) Reaction time as a function of retinal location. Vision Res. 6, 729-732.

Rains J. D. (1963) Signal luminance and position effects in human reaction time. Vision Res. 3. 239-251.

Sanders A. F. (1963) The Selective Process in the Functional Visual Field, pp. 32-35. Institute for Perception RVO TNO, Soesterberg.

Schiepers C. W. J. (1974) Response latencies in parafoveal word recognition. I.P.O. Ann. Prog. Rept 9, 99-103.

Thomas E. L. and O'Beirne H. (1967) Curvature in the saccadic movement. Archs Ophthul. 77, 105-109.

Weber R. B. and Daroff R. B. (1972) Corrective movements following refixation saccades: type and control system analysis. Vision Res, 12, 467-475.

Wheeless L. L., Cohen G. H. and Boynton R. M. (1967) Luminance as a parameter of the eye movement control system. J. opt. Soc. Am. 57, 394-400.

Williams L. G. (1966) Target conspicuity and visual search. Hum. Factors 8, 80-92. 